\title{
CORRECTION
}

\section{Correction: Incidence of neonatal hypertension from a large multicentre study [Assessment of Worldwide Acute Kidney Injury Epidemiology in Neonates-AWAKEN]}

Emily J. Kraut ${ }^{1}$, Louis J. Boohaker ${ }^{2}$, David J. Askenazi ${ }^{2}$, Jeffery Fletcher ${ }^{1,3}$ and

Alison L. Kent ${ }^{1,4}$ on behalf of the Neonatal Kidney Collaborative (NKC)

Pediatric Research (2018) 84:314; https://doi.org/10.1038/s41390-018-0107-8

Correction to: Pediatric Research https://doi.org/10.1038/s41390018-0018-8; published online 23 May 2018

The original version of this Article omitted the NKC Contributors author, Jonathon Swanson MD, from the University of Virginia Children's Hospital, Charlottesville, Virginia, USA.
The PDF and HTML versions of the paper have been modified accordingly.

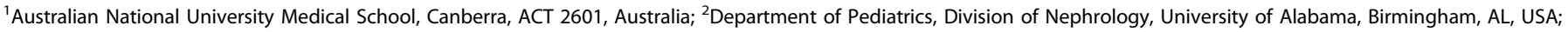

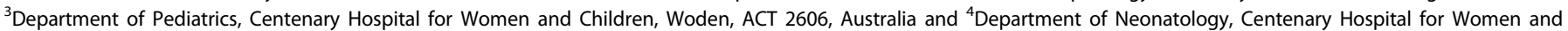
Children, Woden, ACT 2606, Australia

Correspondence: AlisonL Kent (alison.kent@act.gov.au)

Published online: 8 August 2018 